\title{
Complementary and Alternative Medicine versus Conventional Medicine Use in Thalassemia Patients
}

\author{
Wan Ismahanisa Ismail1', Mohamed Azmi Ahmad Hassali2, Maryam Farooqui ${ }^{3}$, \\ Muhammad Nabil Fikri Roslan ${ }^{1}$ Nazri Che Dom ${ }^{4}$ \\ 1 Faculty of Health Sciences,Universiti Teknologi MARA, Cawangan Pulau Pinang, Malaysia \\ 2 School of pharmaceutical sciences, Universiti Sains Malaysia, Penang, Malaysia \\ ${ }^{3}$ Department of Pharmacy Practice, Unaizah College of Pharmacy, Qassim University, Qassim, Saudi Arabia \\ ${ }^{4}$ Centre of Environmental Health \& Safety,Faculty of Health Sciences, UiTM Cawangan Selangor, Puncak Alam, Malaysia \\ ismahanisa@uitm.edu.my; azmihassali@gmail.com.my; M.Farooqui@qu.edu.sa; nabil0600@uitm.edu.my; nazricd@uitm.edu.my \\ Tel: 0184026428
}

\begin{abstract}
Background: This study explores thalassemia patients' perceptions concerning the effectiveness of conventional therapies for Thalassemia healthcare. Method: The semi-structured interviews were audiotaped, transcribed verbatim, and translated into English. Results: Nearly all thalassemia patients reported to have relied on conventional treatment methods to treat and reduce the severity of their disease. Few patients reported not to comply with their treatment procedures due to fear of infection through blood transfusion, surgery and organ failure. Conclusions: In conclusion, patients showed positive views about the conventional therapies carried out for Thalassemia.
\end{abstract}

Keywords:: Thalassemia; qualitative; conventional; complementary and alternative medicine

eISSN: 2398-42870 2021. The Authors. Published for AMER ABRA cE-Bs by e-International Publishing House, Ltd., UK. This is an open access article under the CC BYNC-ND license (http://creativecommons.org/licenses/by-nc-nd/4.0/). Peer-review under responsibility of AMER (Association of Malaysian Environment-Behaviour Researchers), ABRA (Association of Behavioural Researchers on Asians/Africans/Arabians) and CE-Bs (Centre for Environment-Behaviour Studies), Faculty of Architecture, Planning \& Surveying, Universiti Teknologi MARA, Malaysia.

DOI: https://doi.org/10.21834/ebpj.v6i16.2665

\subsection{Introduction}

Thalassemia disease is medically considered a genetic disorder. Those diagnosed with Thalassemia are chronically ill from birth and therefore are subject to conventional treatment, adhering to the procedures that may extend their lifespan. Many related studies addressing conventional treatment issues for thalassemia patients have been reported in the literature[ (Atkin, Ahmad, \& Anionwu, 1998). Thalassemia patients are categorized under a group classified as severe or chronic illness and use conventional medicine since birth. Concerning the prevalence of thalassemia disease, an estimated 2.5\%-25\% of the Mediterranean Basin, the Middle East, the tropical and subtropical regions of Africa, the Asian subcontinent, and Southeast Asia were reported diagnosed with it (Weatherall, 2010). In Malaysia, 6,623 patients were registered with the Malaysian Thalassemia Registry as of 2014 (Hishamshah,2015). Thalassemia disease treatment always focuses on blood transfusion therapy, oral iron chelation therapy, splenectomy, and other associated complications such as endocrinopathies and cardiac (Rachmilewitz \& Giardina, 2011).In previous study showed that $68.5 \%$ thalassemia patients using CAM at least once during their life(Bordbar et.al,2017). Early complications may usually occur about blood transfusions while late complications occur due to iron overload and more importantly, the disease being treated poorly (Ismahanisa

eISSN: 2398-4287@ 2021. The Authors. Published for AMER ABRA cE-Bs by e-International Publishing House, Ltd., UK. This is an open access article under the CC BYNC-ND license (http://creativecommons.org/licenses/by-nc-nd/4.0/). Peer-review under responsibility of AMER (Association of Malaysian Environment-Behaviour Researchers), ABRA (Association of Behavioural Researchers on Asians/Africans/Arabians) and CE-Bs (Centre for Environment-Behaviour Studies), Faculty of Architecture, Planning \& Surveying, Universiti Teknologi MARA, Malaysia.

DOI: https://doi.org/10.21834/ebpj.v6i16.2665 
Ismail, Ahmad Hassali, Mohamed Azmi, Maryam Farooqui, Fahad Saleem, 2016). The aims of this study was set to determine the perceptions the effectiveness use of conventional treatment among thalassemia patients.

\subsection{Materials and methods}

\subsection{Study design and sampling method}

Joint ethical committees approved the study of the School of Pharmaceutical Sciences, USM and Lam Wah Ee Hospital on Clinical Studies in Malaysia [reference: USM-HLWE/IEC/2015 (002)]. The study was conducted from July until October in 2015 at the Kedah Thalassemia Society Centre, Alor Star, in Kedah, i.e., one of the four states in the northern region of Peninsular Malaysia. This centre was the place that thalassemia patients do their activities and counselling also getting information regarding thalassemia. According to the Malaysian Thalassemia Registry 2014, the northern region recorded the highest number of thalassemia patients. In line with such a scope, purposive and theoretical samplings were employed to explore the issues with the perceptions of Thalassemia and its treatment used among thalassemia patients (Bordbar et.al,2017). Recruitment of patients was made until the researchers reached theoretical saturation, i.e., no new information emerged after the subsequent interviews, thus fulfilling theoretical sampling requirements(Auerbach \& Silverstein, 2003). The participants were selected 18 years of age or older diagnosed with thalassemia disease and agreed to participate in this study. The interview sessions were administered until a saturation point was reached, i.e., no new information acquired from the following interviews. Within the four months of recruiting thalassemia patients for the study, a total of 21 patients agreed to participate and were interviewed. It has to be noted that there were patients who could not participate in this study owing to health problems or were not accessible on the days when interviews were administered.

\subsection{Instrument and data collection}

The interview session was administered by adhering to the interview guide prepared based on a comprehensive review of previous studies. Participants were asked about issues that they could relate to thalassemia treatment. Open-ended questions were employed in the interview sessions to offer the patients the most outstanding possible chances to share their perspectives. At the beginning stage, a pilot study was carried out involving only four interview sessions to ensure any issues or barriers with the interview questions. That may assure that the study could be conducted accordingly and amend the interview guide if necessary(Kim, 2011). Each in-depth semistructured interview session lasted approximately 45 to 60 minutes. The interviews were conducted in the Malay language. Specifically, the interviews involved one patient for each session, with a total of 21 patients. At the $19^{\text {th }}$ interview session, the saturation point was reached; however, two follow-up interviews had to be conducted to triangulate the findings. The interview sessions were recorded digitally and were transcribed in English by the principal investigator. The patients were categorized with unique numbers (P01-P21) to assure that participants' identities were kept confidential. The principal investigator, who is the head of this research project was present in the entire interview sessions. The interview sessions were transcribed verbatim. The transcripts were reviewed by the researchers and were subsequently sent to the patients for member-checking purposes. The transcripts were subjected to thematic content analysis, including coding and identifying the comparative analytic process to determine the emerging categories. This was jointly carried out by the principal investigator and the co-researchers who were notified of this study's aims and objectives. The principal investigator and the patients in the study shared a similar cultural background, i.e., they spoke Malay in the Kedahan dialect and English. Therefore, communication barriers did not stand in their way. The data was further analysed to assess the behaviour of each participant based on unique codes (Bahal \&Edwards2015).

\subsection{Findings}

A total of twenty-one patients (P01-P21) between the ages of 18 and 58 (Mean $=29$ years) were interviewed. As the Malays constitute the leading ethnic group in Malaysia, they made up the highest $(n=17)$ number of patients in the sampled group of patients, followed by the Chinese $(n=4)$. Most of the patients were from a low-income group seeking treatment in government hospitals. It was discovered that all the patients belonged to either $\beta$ thalassemia major or intermediate thalassemia. Seeking treatment at private hospitals may not be a sensible move as almost no insurance companies cover thalassemia patients' medical cost. Therefore, these patients had no other choice than seeking treatment at government hospitals. The demographic data of the patients are summarized in Table 1. The conventional treatment offered by hospitals includes blood transfusion, surgery and chelation therapy. It is noteworthy that traditional healing methods may consist of any treatment other than what is being provided by the hospitals. Thematic content analysis revealed three themes:1) perceived conventional medicine is effective, 2) perceived evidence from the research and 3) Fear of the effects of conventional treatment. 
Table 1: Demographic and clinical characteristic of participant

\begin{tabular}{|c|c|c|c|c|c|c|c|c|c|}
\hline ID & Age & Sex & Ethnicity & Religion & $\begin{array}{l}\text { Marital } \\
\text { Status }\end{array}$ & $\begin{array}{l}\text { Socio- } \\
\text { economic } \\
\text { status }\end{array}$ & Educational background & $\begin{array}{l}\text { Currently } \\
\text { Using CAM }\end{array}$ & Type of Thalassemia \\
\hline P01 & 39 & Female & Malay & Islam & Married & Middle & Secondary & YES & Intermediate Thalassemia \\
\hline P02 & 27 & Male & Malay & Islam & Unmarried & low & Secondary & YES & $\beta$-Thalassemia major \\
\hline $\mathrm{PO3}$ & 32 & Female & Malay & Islam & Widowed & low & Secondary & YES & Intermediate Thalassemia \\
\hline P04 & 25 & Female & Malay & Islam & Unmarried & low & Diploma/Matriculation & YES & $\beta$-Thalassemia major \\
\hline P05 & 23 & Female & Malay & Islam & Unmarried & low & Secondary & YES & $\beta$-Thalassemia major \\
\hline P06 & 30 & Female & Malay & Islam & Married & Middle & Secondary & YES & Intermediate Thalassemia \\
\hline P07 & 32 & Female & Malay & Islam & Unmarried & Middle & Diploma/Matriculation & YES & Intermediate Thalassemia \\
\hline P08 & 32 & Female & Malay & Islam & Married & Middle & Secondary & YES & Intermediate Thalassemia \\
\hline P09 & 20 & Female & Malay & Islam & Unmarried & low & Secondary & YES & Intermediate Thalassemia \\
\hline $\mathrm{P} 10$ & 24 & Female & Malay & Islam & Unmarried & low & Secondary & YES & $\beta$-Thalassemia major \\
\hline P11 & 21 & Female & Malay & Islam & Unmarried & Middle & Diploma/Matriculation & YES & $\beta$-Thalassemia major \\
\hline $\mathrm{P} 12$ & 32 & Female & Malay & Islam & Unmarried & low & Secondary & YES & $\beta$-Thalassemia major \\
\hline $\mathrm{P} 13$ & 31 & Male & Malay & Islam & Unmarried & low & Secondary & YES & $\beta$-Thalassemia major \\
\hline P14 & 23 & Female & Malay & Islam & Unmarried & low & Certificate MARA & YES & Intermediate Thalassemia \\
\hline P15 & 25 & Male & Malay & Islam & Unmarried & low & Secondary & YES & $\beta$-Thalassemia major \\
\hline P16 & 27 & Female & Malay & Islam & Unmarried & Middle & Diploma/Matriculation & YES & $\beta$-Thalassemia major \\
\hline $\mathrm{P} 17$ & 23 & Male & Malay & Islam & Unmarried & low & Diploma/Matriculation & YES & $\beta$-Thalassemia major \\
\hline P18 & 58 & Male & Chinese & Buddhism & Married & low & Primary & NO & Thalassaemia carrier \\
\hline P19 & 20 & Male & Chinese & Buddhism & Unmarried & low & Secondary & NO & Thalassaemia carrier \\
\hline P20 & 38 & Male & Chinese & Buddhism & Married & Middle & Diploma/Matriculation & YES & Thalassaemia carrier \\
\hline P21 & 39 & Female & Chinese & Buddhism & Married & Middle & Secondary & YES & Thalassaemia carrier \\
\hline
\end{tabular}

\subsection{Perceived Effectiveness of Conventional Treatment}

It is noteworthy that for the past 40 years, the treatment for Thalassemia in Malaysia has significantly improved and patients are satisfied with the services offered during the treatment compared to previous years. Blood transfusion is the mainstay of thalassemia treatment for individuals with either intermedia or major. It is needed to prevent the growth of body, skeletal and endocrinologic complications in thalassemia major. This is because the patients need to seek necessary treatment to continue their life as they do not have any other options. Following the blood transfusion, the patients will continue with chelation therapy because the blood transfusion will increase the gastrointestinal absorption, which leads to the overloading of iron. The overload iron is the cause of morbidity and mortality in Thalassemia.

Thalassemia patients perceive that the treatments were adequate because the disease symptoms were reduced after their treatment, such as reduced ferritin levels and increased haemoglobin levels. Following are the responses from the patients:

"I think that modern treatment is good and effective for my sickness". [P1, 38 years, Female, Malay, Thalassemia intermedia]

"I believe in the effectiveness of modern treatment because it works faster and is more effective even though those suffering from Thalassemia cannot be cured. Modern treatment comes with evidence from research compared to the lack of evidence from the traditional ones. Today, the current conventional treatment is more effective compared to that of the previous years". [P10, 23 years, Female, Malay, $\beta$-Thalassemia Major]

Therefore, the patients deemed that conventional treatment can reduce the sickness rather than doing nothing.

\subsection{Perceived Evidence from the Research}

The conventional treatments of Thalassemia provided by the hospital have improved. The sampled patients perceived that these treatments, which were done by experimental, can be described as safe, expensive, advanced and can. The sampled patients perceived that these treatments, which were done by experimental, can be described as safe, expensive, progressive and can cure or reduce the symptoms. Moreover, the patients perceived that the iron-chelating process reduces the iron loading inside their body because iron accumulation in the tissues causes the progressive organ to dysfunction and may cause fatal. It should be noted that patients need to follow all the therapy to prevent complications. Following were the patients' responses:

I feel that modern treatments respond faster than traditional treatments, helping me live my life as usual.[Patient 9: 19years, Female, Malay, Thalassemia intermedia]

Feels and believes that modern medicine works for those with Thalassemia. They respond faster compared to traditional treatments. The expert does the modern treatments, and they establish by continuous research compare to the traditional [Patient 7: 29yrs, Female, Malay, Thalassemia intermedia] 
These patients deemed that the expensive, highly sophisticated and advanced technology treatments may reduce their illness and problems.

"I believe in the effectiveness of modern treatment because it works faster and is very expensive. Before this, we had to buy our filter bag, unlike these days. It is more effective even though those suffering from Thalassemia cannot be cured". [P10, 23 years, Female, Malay, $\beta$ Thalassemia Major]

\title{
3.3 Fear of the effects of conventional treatment.
}

Some thalassemia patients who were chronically ill and underwent conventional treatment shortly after giving birth may persist the illness until death. Although many treatments are deemed beneficial, thalassemia patients still felt that the treatments are associated with risks.

\subsubsection{Fear of blood transfusion}

Some of the patients developed fear on the continuous blood transfusion as it may lead to iron overload and risk of bacterial and viral infections.

"For the blood transfusion, I am a bit worried whenever I think of the possible risks of getting infected with HIV and many more. But, gradually, I have got used to it. Now, whenever it crosses my mind, I quickly pray and hope for the best". [P12, 32 years, Female, Malay, $\beta$-Thalassemia Major]

\begin{abstract}
"Antibiotics don't work. I am still sick. I had to be warded for five months, unconscious due to brain infection or brain abscess. The doctor, said that it was because of the blood transfusion done on me". [P1, 38 years, Female, Malay, Thalassemia intermedia]

"Each time I had to do the blood transfusion, I am worried that I will get infected by HIV and hepatitis C ". [Patient 2: 26years, Male, Malay, $\beta$-Thalassemia Major]
\end{abstract}

"My liver often swells maybe due to the frequent blood transfusion each month. My spleen often swells too. Sometimes I wonder if I keep on doing blood transfusion, am I going to be infected with Hepatitis $C$ virus for example, because many of those with Thalassemia got hepatitis C". [P5, 22 years, Female, $\beta$-Thalassemia Major]

The sampled thalassemia patients were worried about the conventional treatment's inherent long-term adverse effects, potentially life-threatening. The sampled patients were also sceptical about the severe co-morbidities such as hepatic fibrosis, cirrhosis, pulmonary dysfunction, multiple endocrinopathies and growth failure. These were the concerns among thalassemia patients every time they need to do a blood transfusion.

\subsubsection{Fear of iron chelation therapy}

The sampled participants were concerned about the problem involving the long term chelation therapy. An iron chelator is required in these patients following 10-20 units of packed red blood cells or the serum ferritin, which is more than $1000 \mathrm{ng} / \mathrm{mg}$. They were concerned about the continuous chelator therapy effect, which defers from the healthcare providers' instructions. The patients were reportedly suffered from side effects after the consumption of exjade, including pain, itchiness and swelling at the injection site. It is noteworthy that these have made the patients to ignore and missed the consumption of exjade. This is evident in the participant's responses below:

"I frequently vomit after taking exjade and then changed to L1. Injecting dysferal causes my skin to itch. My spleen had been removed. Then I took penicillin. I am easily tired because I have to take injections often. I often tried to escape from getting treatments until I am not well. If I take medicines, I will sleep all day because the medicines make me feel sleepy. It is very tiring and boring to inject my self every day and every night. Any alternative treatment, I will try it because I do not want to continue this treatment my whole life and keep on depending on medicines. I do not want it to interfere with my life". [P15, 24 years, Male, Malay, $\beta$ Thalassemia Major]

"Having injected dysferal four bottles a day for six days straight sometimes makes me difficult to move, and my skin would become itchy". [P10, 23 years, Female, Malay, $\beta$-Thalassemia Major]

Inject dysferal four bottles a day for six days straight, and sometimes it made me difficult to move, and my skin got itchy. I also got ulcers often but do not because of what or which medicines. Sometimes I think of changing blood, but I must be brave and willing to take risks to live. [Patient 10: 23years, Female, Malay, $\beta$-Thalassemia Major]

Based on the participant's responses, the common reason for the unwillingness to go for iron chelation treatment was the side effects. As a result, the patients opt for complementary and alternative medicine to replace iron chelation treatment.

\subsubsection{Fear of surgery}

The sampled patients were afraid after their first surgery of spleen. After years of undergoing blood transfusion, the patients will experience a splenectomy. This happens when the patients are required to have a transfusion which is more than $200 \mathrm{ml}$ packed cell per kilogram body weight, and this may have a significant effect in diminishing the iron accumulation. The patients were afraid of the potential of hepatitis and other infections during the blood transfusion procedure, especially after spleen removal. They were also concerned about removing the liver after spleen surgery because it may enlarge after the regular blood transfusion. 
"I had to remove my spleen because it had been swollen due to the continuous blood transfusion done on me". [P8, Female, Malay, $\beta$ Thalassemia Major]

"But if I can get better treatment, for instance, the traditional way, I would stop undergoing the treatment I am doing now as I am not sure of its consequences if I continue with this treatment". [P13, 30 years, Male, Malay, $\beta$-Thalassemia Major]

The fear of side effects of the treatments may result in the patients' unwillingness to comply with the conventional treatment, which has resulted in the usage of complementary and alternative medicine as therapies. However, the concurrent use of CAM with conventional treatment may enhance or reduce the conventional medicines' side effects. Furthermore, proper counselling and ongoing education between the health practitioners and noncompliant patients and reduced side effects on conventional medicine are deemed essential to overcome the patients' fear.

\subsection{Discussion}

This study aimed to look into the perceptions and experience of conventional treatment within a group of thalassemia patients. Studying the patients' perceptions about conventional treatment is of utmost importance as the findings may inform if they comply with or forgo the treatment procedures. Conventional treatment because this treatment only can prolonged their life .However, when taking blood transfusion they also can suffer from complication(Borgna et.al, 2017). In the present study, the patients perceived that the conventional treatment was beneficial and effective in reducing the severity of Thalassemia. Clinical features and management of Thalassemia have presently improved considerably with the advanced and sophisticated technologies being incorporated compared to the past(Cunningham, Macklin, Neufeld, Cohen, \& Thalassemia Clinical Research Network, 2004). However, significant effects from such methods on patients have yet to be seen. The thalassemia patients sampled in this study reported that they fear conventional treatment effects such as blood transfusion, fear of iron chelation therapy and surgery. Individuals belonging to the category of thalassemia major usually undergo comprehensive conventional treatment for a lifetime. However, the regular blood transfusion may enhance the iron overload in various endocrine organs and form alloantibodies after the multi transfused blood procedures(Dogra, Sidhu, Kapoor, \& Kumar, 2015; W. ismahanisa Ismail, Al-Hassan, \& Shatar, 2016; Jensen et al., 1998).

Moreover, these patients also raised concerns about potentials infections that they may suffer from blood transfusions such as hepatitis, HIV and other infectious diseases. It has been reported that thalassemia patients who received multiple blood transfusion can cause the risk of seroconversion of hepatitis B and hepatitis C virus (Lee, Teh, \& Chan, 2005). The iron overload in the patients' body may have to be removed using iron-chelating therapy. The patients' fear of the chelation process could be due to the local side effects resulting from the treatment using deferoxamine.

The treatment of iron overload is often associated with complications about the growth of deficiency, delayed puberty, hypothyroidism, diabetes and osteoporosis (Galanello \& Origa, 2010). Previous studies reported in the literature showed that traditional and complementary medicine, lack of family support, technical problems, and limited access to healthcare programs contribute to noncompliance with this chelation agent. The patients preferred the use of deferasirox compared to deferoxamine as it can be consumed. Still, it has to be highlighted that the deferoxamine is much cheaper and more effective in reducing iron overload (Cunningham et al., 2004; Lee, Toh, Chai, \& Soo, 2011) deferoxamine is provided at government hospitals in Malaysia for free of charge. Though notably cheaper the patients' noncompliance about using deferoxamine, the cost of deferoxamine may result in complications and therefore may involver higher cost to treat the patients who have problems(Delea et al., 2007; Fisher et al., 2013). The thalassemia patients also admitted that they feared the splenectomy's surgery and was afraid of the second surgery because their liver may swell. Postsplenectomy infection and the splenectomy risk may generally delay until more than five years (Olivieri \& Brittenham, 1997). However, the splenectomy may happen to thalassemia patients to avoid the splenic enlargement, leukopenia, or other thrombocytopenia and iron overload despite useful chelation(Borgna Pignatti\& Cappellini, 2005; Galanello \& Origa, 2010).Nevertheless this study have several limitations , the respondents of this study from low income and middle class group of people.It should conduct also among thalassemia patients with high income group to determine whether they are using CAM only as alternative or as compliment to the thalassemia treatment .Further analysis of the thalassemia patients may have to be carried out to avoid the noncompliance and delay seeking treatment. Failing to seek appropriate treatment for this disease at an early stage may result in complications going unnoticed. Lives of these patients may end fatally (A. Ismail, Campbell, Ibrahim, \& Jones, 2006; Wan Ismahanisa Ismail et al., 2016; Ismail, Ahmad Hassali, Farooqui, Saleem, \& Roslan, 2018)).

\subsection{Conclusions \& Recommendations}

Based on the present study's findings, the researchers concluded that these patients perceived the benefits and the effectiveness of conventional medicine. They were persuaded to comply with the treatments diligently and consistently consuming their drugs. It should be noted that the patients should not miss even a single dose of their medication as it may bring negative implications. However, some patients with different perspectives view some patients with different views from different conventional treatment perspectives. They were worried and were afraid of pre and post-treatment effects. The present study's findings also provide some understanding and views among thalassemia patients regarding modern treatment. This information is pivotal in designing effective educational and intervention programmes such as counselling between the healthcare providers and the patients to know the problem and come out with solutions 
to overcome these problems. The level of good compliance with the medication may be challenging in the population of the present study. Still, it is essential to avoid early mortality among thalassemia patients. Since patient showed dissatisfaction towards conventional treatment received further study needed on how CAM practitioners treat the thalassemia patients.

\section{Acknowledgements}

We wish to thank all the participants who participated in the study and to thank Club Thalaasemia Kedah for their permission to conduct the research.

\section{Paper Contribution to Related Field of Study}

Paper contribution in academic research related to Complementary and alternative medicine, conventional medicine and also thalassemia patients.

\section{References}

Atkin, K., Ahmad, W. I. ., \& Anionwu, E. N. (1998). Screening and counselling for sickle cell disorders and thalassaemia: The experience of parents and health professionals. Social Science \& Medicine, 47(11), 1639-1651. http://doi.org/10.1016/S0277-9536(98)00261-5

Auerbach CF, Silverstein LB. (2003) Qualitative data: an introduction to coding and analysis. New York University Press; 2003.

Boardbar M, Pasalar M,Safaei S,Kamfiroozi R,Zareifar S,Zekayat Omidreza,Haghpanah (2017) Complementary and alternative medicine use in thalassemia patients in Shiraz, southern Iran:A cross sectional study, Journal of traditional and complementary medicine, 141-146

Borgna-Pignatti, C., \& Cappellini, M. (2005). Survival and complications in Thalassemia. Annals of the New. Retrieved from http://onlinelibrary.wiley.com/doi/10.1196/annals.1345.006/full

Cunningham, M. J., Macklin, E. A., Neufeld, E. J., Cohen, A. R., \& Thalassemia Clinical Research Network. (, 2004). Complications of beta-thalassemia major in North America. Blood, 104(1), 34-9. http://doi.org/10.1182/blood-2003-09-3167

Dr Hishamshah $8^{\text {th }}$ National Thalassemia Seminar in conjunction 1st Asean thalassemia forum May 2017

Dogra, A., Sidhu, M., Kapoor, R., \& Kumar, D. (2015). Study of red blood cell alloimmunization in multi transfused thalassemic children of Jammu region. Asian Journal of Transfusion Science, 9(1), 78-81. http://doi.org/10.4103/0973-6247.150958

Delea, T. E., Edelsberg, J., Sofrygin, O., Thomas, S. K., Baladi, J.-F., Phatak, P. D., \& Coates, T. D. (2007). Consequences and costs of noncompliance with iron chelation therapy in patients with transfusion-dependent Thalassemia: a literature review. Transfusion, 47(10), 1919-1929. http://doi.org/10.1111/j.1537-2995.2007.01416.x

Fisher, S. A., Brunskill, S. J., Doree, C., Gooding, S., Chowdhury, O., \& Roberts, D. J. (2013). Desferrioxamine mesylate for managing transfusional iron overload in people with transfusion-dependent thalassaemia. In D. J. Roberts (Ed.), Cochrane Database of Systematic Reviews. Chichester, UK: John Wiley \& Sons, Ltd. http://doi.org/10.1002/14651858.CD004450.pub3

Galanello, R., \& Origa, R. (2010). Beta-thalassemia. Orphanet Journal of Rare Diseases, 5(1), 11. http://doi.org/10.1186/1750-1172-5-11

Jensen, Tuck, Agnew, Koneru, Morris, Yardumian, ... Wonke. (, 1998). High prevalence of low bone mass in thalassaemia major. British Journal of Haematology, 103(4), 911-915. http://doi.org/10.1046/j.1365-2141.1998.01108.x

Ismahanisa Ismail, W., \& Ahmad Hassali, Mohamed Azmi, Maryam Farooqui, Fahad Saleem, H. A. (2016). PERCEPTIONS OF THALASSEMIA AND ITS TREATMENT. Australasian Medical Journal, 9(5). http://doi.org/10.4066/AMJ.2016.2607

Ismail, A., Campbell, M. J., Ibrahim, H. M., \& Jones, G. L. (2006). Health-Related Quality of Life in Malaysian children with thalassaemia. Health and Quality of Life Outcomes, 4(1), 39. http://doi.org/10.1186/1477-7525-4-39

Ismail, W. I., Ahmad Hassali, M. A., Farooqui, M., Saleem, F., \& Roslan, M. N. F. (2018). Complementary and alternative medicine (CAM) disclosure to health care providers: A qualitative insight from Malaysian thalassemia patients. Complementary Therapies in Clinical Practice, 33. http://doi.org/10.1016/j.ctcp.2018.06.004

Kim, Y. (2011). The Pilot Study in Qualitative Inquiry: Identifying Issues and Learning Lessons for Culturally Competent Research. Qualitative Social Work, 10(2), 190206. http://doi.org/10.1177/1473325010362001

Lee, W. S., Teh, C. M., \& Chan, L. L. (2005). Risks of seroconversion of hepatitis B, hepatitis C and human immunodeficiency viruses in children with multi transfused thalassaemia major. Journal of Paediatrics and Child Health, 41(5-6), 265-268. http://doi.org/10.1111/j.1440-1754.2005.00608.x

Lee, W. S., Toh, T. H., Chai, P. F., \& Soo, T. L. (2011). Self-reported level of and factors influencing the compliance to desferrioxamine therapy in multi transfused thalassaemias. Journal of Paediatrics and Child Health, 47(8), 535-40. http://doi.org/10.1111/j.1440-1754.2011.02017.x

Olivieri, N. F., \& Brittenham, G. M. (1997). Iron-Chelating Therapy and the Treatment of Thalassemia. Blood, 89(3)

Rachmilewitz, E. A., \& Giardina, P. J. (2011). How I treat thalassemia. Blood, 118(13). 
Ismail , W.I., et.al., AicQoL2021, AMER International Conference on Quality of Life, Colmar Tropicale, Bukit Tinggi, Malaysia, 17-18 Mar 2021, E-BPJ, 6(16), Mar 2021 (pp.105-111)

Thalassemia International Federation: A Guidelines for the clinical management thalassemia 2nd edition.2008[http://www.thalassemia.org.cy] (retrieved on 2017)

Weatherall, D. J. (2010). Thalassemia as a global health problem: recent progress toward its control in the developing countries. Annals of the New York Academy of Sciences, 1202 17-23. http://doi.org/10.1111/j.1749-6632.2010.05546.x 